\title{
Pedido de registro de marca e controle jurisdicional
}

\author{
Autor: Antonio André Muniz de Souza \\ (Procurador Federal na Procuradoria Regional do INPI em São Paulo)
}

| Artigo publicado em 16.09.2005 |

\section{Resumo}

Trata-se de artigo que objetiva analisar a possibilidade de utilizar-se do Poder Judiciário para impugnar pedido de registro de marca, antes de o INPI proceder ao seu exame.

Palavras-chave: pedido de registro de marca; controle jurisdicional; impugnação; INPI; ação cominatória

O registro de marca é bem imaterial cuja propriedade confere ao seu titular exclusividade de uso em todo o território nacional. Para obtêlo, em princípio, devem ser requeridos sinais distintivos visualmente perceptíveis que não encontrem vedações na Lei no 9.279/96, diploma regulador de direitos e obrigações relativos à propriedade industrial (por isso denominada Lei da Propriedade Industrial - LPI). O pedido segue o curso previsto nos arts. 155 a 166 da LPI, sendo, ao final, após exame técnico, deferido ou indeferido, com expedição do certificado de registro, caso concedido. Toda a tramitação se dá perante o Instituto Nacional da Propriedade Industrial - INPI, autarquia federal que tem por finalidade principal executar, no âmbito nacional, as normas de propriedade industrial.(1)

Muitas vezes, o requerente da marca passa a usá-la de fato em seus produtos ou serviços, antes da concessão do registro. Essa utilização, que não tem amparo no título de propriedade, pode estar violando signos distintivos protegidos de terceiros, como no caso de a marca usada para reproduzir ou imitar marca já registrada por outrem, com afinidade mercadológica e suscetibilidade de causar confusão ao consumidor (art. 124, XIX, LPI). Para esses casos, o ordenamento jurídico-processual brasileiro oferece ao titular do direito lesionado ação para solicitar ao Poder Judiciário tutela jurisdicional específica, consistente em obrigação de não fazer, para inibir o uso indevido da marca, sob pena de multa e sem prejuízo de indenização por perdas e danos (arts. 287 e 461 do CPC).

Veja-se que a tutela obtida nessas ações é direcionada a impedir que determinada pessoa use uma dada marca da qual não tem registro. Todavia, alguns demandantes pretendem ir além, solicitando ao juiz da causa providências de interferência no pedido de registro em 
tramitação no INPI. Sem percepção para a adequação processual do pleito, requerem que o magistrado determine o "sobrestamento", a "suspensão", o "arquivamento", a "extinção", o "indeferimento" ou até mesmo a "nulidade" do pedido em andamento. Tais requerimentos, no entanto, refogem à competência do Judiciário e implicam falta de interesse de agir.

Nos termos do art. 129, caput, da LPI, só tem direito de uso exclusivo da marca quem adquire sua propriedade por registro validamente expedido. O simples pedido de registro depositado na autarquia confere mera expectativa de direito ao requerente. Uma vez que o INPI ainda não examinou o pedido, evidentemente não há o que ser impugnado judicialmente.

De acordo com a doutrina pátria, o interesse processual, anteriormente designado interesse de agir, se assenta na idéia da utilidade e da necessidade. É a busca da prestação jurisdicional do Estado, para a tutela da pretensão deduzida (interesse primário). Nesse sentido, o interesse processual (secundário, subsidiário ou instrumental) visa à obtenção, porque necessário e útil, da providência jurisdicional quanto ao interesse substancial ou primário contido na pretensão e tutelado pelo direito objetivo.

Define-o Ovídio A. Baptista da Silva(2) como a necessidade que deve ter o titular do direito de servir-se do processo para obter a satisfação do seu interesse material, ou para, por meio dele, realizar o seu direito. A necessidade da tutela jurisdicional se evidencia pelo fato de não ter o demandante outro meio para obter aquilo que almeja senão a via do Poder Judiciário. Nessa linha, definem Antônio Carlos de Araújo Cintra, Ada Pellegrini Grinover e Cândido Rangel Dinamarco: (3)

“Interesse de agir - Essa condição da ação assenta-se na premissa de que, tendo embora o Estado o interesse no exercício da jurisdição (função indispensável para manter a paz e a ordem na sociedade), não lhe convém acionar o aparato judiciário sem que dessa atividade se possa extrair algum resultado útil. É preciso, pois, sob esse prisma, que, em cada caso concreto, a prestação jurisdicional solicitada seja necessária e adequada.

Repousa a necessidade da tutela jurisdicional na impossibilidade de obter a satisfação do alegado direito sem a intercessão do Estado ou porque a parte contrária se nega a satisfazê-lo, sendo vedado ao autor o uso da autotutela, ou porque a própria lei exige que determinados direitos só possam ser exercidos mediante prévia declaração judicial (são as chamadas ações constitutivas necessárias, no processo civil e a ação penal condenatória, no processo penal - v. supra, n. 7)" 
Assim, uma vez que o INPI ainda não concedeu o registro requerido, não há o que ser impugnado judicialmente, restando nítida a completa ausência de interesse processual.

Cumpre à autarquia federal, como componente da Administração Indireta da União, a concessão de registro de marcas, cujas condições estão definidas pela Lei da Propriedade Industrial e legislação aplicável. Por isso, a interferência na tramitação dos pedidos implica a assunção, pelo Poder Judiciário, das atribuições conferidas ao INPI, à medida que faz um pré-julgamento daquilo que pode ou não ser registrado, violando o princípio da separação de poderes.

Não há dúvida de que a separação de poderes, além de pressupor as funções típicas de cada Poder, assegura o controle de um Poder pelo outro. Nesse sentido, o Poder Judiciário pode, por meio de seus órgãos, proceder ao controle de legalidade dos atos exarados por outros Poderes. Ocorre que, quando se trata de pedido, não houve ainda qualquer ato praticado pela autarquia. Logo, suspender 0 andamento do pedido de marca, negar-lhe prosseguimento administrativo ou indeferi-lo significa antecipar o julgamento de um objeto afeto às funções legais do INPI.

O próprio Poder Judiciário reconhece tal impossibilidade:

“I - ADMINISTRATIVO - PROPRIEDADE INDUSTRIAL - MARCAS 'COKDOG E COKDOB' - USO DAS EXPRESSÕES 'COKE E COCA-COLA' - COLIDÊNCIA - ANULAÇÃO DE REGISTRO - TRATANDO-SE DE MARCAS RECONHECIDAMENTE NOTÓRIAS, HÁ QUE SER ANULADO O REGISTRO DA MARCA 'CODOB', EM FACE DO DISPOSTO NO ART. 65, N.17, DO C.P.I., QUE VEDA O REGISTRO DE MARCAS IDÊNTICAS OU SEMELHANTES PARA PRODUTOS PERTENCENTES A RAMOS DE ATIVIDADES AFINS, OU RELATIVOS, COMO SE VERIFICA NA HIPÓTESE - A 1a RÉ, EM CONSEQÜÊNCIA, DEVERÁ ABSTER-SE DO USO DE IMITAÇÕES ESPECÍFICAS E DETERMINADAS DAS MARCAS EM QUESTÃO - QUANTO À MARCA "COKDOG", HÁ QUE SER REPELIDA A PRETENSÃO DE CONDENAR O INPI A INDEFERIR O SEU REGISTRO, PORQUE ASSIM ESTARIA O JUDICIÁRIO INTERVINDO NO PODER DECISÓRIO DAQUELE ÓRGÃO, ANTECIPANDO UM JULGAMENTO DE SUA COMPETÊNCIA - INDEMONSTRADO NA FASE DE CONHECIMENTO QUALQUER PERDA POR PARTE DAS AUTORAS EM RAZÃO DO USO INDEVIDO DA MARCA PELA 1a RÉ, DESCABE O PEDIDO DE INDENIZAÇÃO.

II - APELAÇÃO DA 'DUMILHO S/A INDÚSTRIA E COMÉRCIO' IMPROVIDA. 
III - APELAÇÃO DA 'THE COCA-COLA COMPANY E OUTRO' PROVIDA PARCIALMENTE." (TRF 2a Região - 1a Turma, Rel. Juiz Frederico Gueiros, AC 9402046224/RJ, j. 02/08/1995, v.u., DJ 04/04/1996)

"ADMINISTRATIVO. MARCA INDUSTRIAL. ANULAÇÃO DE ATOS JURÍDICOS. PEDIDO DE REGISTROS. IMPOSSIBILIDADE JURÍDICA.

I - O ATO ADMINISTRATIVO DO DEFERIMENTO OU INDEFERIMENTO DO PEDIDO DE REGISTRO DA MARCA É QUE SE TORNA PASSÍVEL DE CORREIÇÃO PELA VIA JUDICIAL, SENDO INDEVIDA A ANTECIPAÇÃO DE ANULAÇÃO DO ATO DE PEDIDO DE REGISTRO DA APELADA, POIS QUE LEGÍTIMO E CONSTITUCIONAL O DIREITO DE PETIÇÃO AOS PODERES PUBLICOS.

II - IMPOSSIBI LIDADE JURÍDICA.

III - RECURSO NÃO PROVIDO. SENTENÇA CONFIRMADA." (TRF2a Região- 1a Turma, AC 9102109328/RJ, Rel. JUÍZA LANA REGUEIRA, j. 18/11/1992, v.u., DJ 26/01/1993)

Além disso, o INPI não pode, à luz dos princípios constitucionais que regem a Administração Pública, deixar de proceder à análise de um pedido de registro, eliminando seu trâmite legal, eis que a Lei da Propriedade Industrial, ao atribuir ao Instituto competência exclusiva para conceder os registros de marcas em todo o país, prevê, para tanto, um procedimento administrativo regrado, a ser observado tanto pelo administrador, quanto pelo particular interessado no registro de seu signo marcário, como também por aqueles que se sentirem prejudicados com pedidos de marca de terceiros.

Nesse sentido, a Lei no 9.279/96 estabelece um sistema próprio e específico para impugnação de pedidos de marca alheios. Antes da concessão, cabe ao interessado apresentar oposição (art. 158, LPI). Depois disso, deve-se aguardar eventual concessão do registro, que poderá ser atacado por processo administrativo de nulidade (arts. 168 a 172, LPI) ou ação judicial de nulidade (arts. 173 a 175, LPI). Em ambos, a declaração de nulidade produzirá efeito a partir da data do depósito do pedido (art. 167 do LPI).

Desse modo, há um desencadeamento procedimental que não pode ser rompido. Com o depósito do pedido de registro de marca e sua publicação (art. 158, LPI), a autarquia se vê compelida por força legal a proceder ao seu exame técnico, obedecendo à ordem cronológica de publicação e observando corretamente o procedimento administrativo previsto na LPI. Portanto, a suspensão do processamento de pedido de registro de marca e, com maior gravidade, a imposição de negativa de seguimento podem prejudicar a segurança do sistema atributivo de registro adotado pelo Brasil, 
com indevida usurpação de competência exclusivamente administrativa.

Basta imaginar o quadro assolador, em que todos aqueles que se sentirem ameaçados com pedidos de marca depositados junto ao INPI, em vez de se utilizarem dos meios próprios de impugnação, ingressem no Judiciário para que este, substituindo-se ao órgão administrativo competente, em análise antecipada quanto a outros pedidos, negue seguimento a esses pedidos. Significaria transformar a Justiça em órgão registrador, o que ofende as nobres competências que a Constituição da República Ihe atribuiu.

Há outras sérias implicações que a interferência judicial nos pedidos de registro pode provar. É que, às vezes, determinado pedido em andamento, por anteceder a outros, pode estar servindo de impedimento para estes por colidência. Assim, se uma ordem judicial determinar a suspensão do pedido anterior, todos os demais serão afetados e, por lógico, terão de aguardar o final da ação judicial para análise. I magine-se, então, que estes ainda possam ser impeditivos de outros pedidos posteriores: criar-se-ia um temível efeito cascata.

Outro entrave processual: geralmente, os litigantes solicitam ao Poder Judiciário estadual que notifique o INPI ou se lhe encaminhe ofício para frear ou podar o pedido de marca em andamento. Ora, a providência não pode ser imposta ao Instituto, que não é parte no processo (art. 472, CPC). Ademais, o juízo estadual não é competente para decidir sobre o controle de procedimentos administrativos que tramitam perante entidades autárquicas federais, ex vi do art. 109, inc. I, da Constituição Federal.

Também não se aplica ao tema em discussão a jurisprudência consolidada nos Tribunais pátrios, no sentido de que é desnecessário o esgotamento das vias administrativas para ter acesso ao Poder Judiciário, à luz do art. 5으, XXXV, da Carta Magna. A lesão pelo uso de marca sem registro, sim, deve ser coarctada pela ação cominatória cabível. Já o mero pedido de marca não gera direito de uso exclusivo (art. 129, caput, LPI), e, portanto, a indeclinabilidade da jurisdição não pode ser invocada para o seu exame antecipado pelo órgão judicial, uma vez que não há ato administrativo a ser apreciado e, em decorrência, inexiste lide instaurada.(4)

Pode-se concluir, portanto, que o pedido de registro de marca deve seguir o procedimento previsto na Lei da Propriedade Industrial, que assegura meios adequados de impugná-lo: antes do registro, por meio de oposição (art. 158); depois do registro, mediante processo administrativo de nulidade (art. 168) ou ação judicial de nulidade (art. 173). Em conseqüência, descabe ajuizar demanda solicitando ao Poder Judiciário apreciar o pedido de registro de marca antes do 
exame do INPI, por falta de interesse processual e em respeito ao princípio da separação dos poderes republicanos.

NOTAS DE RODAPÉ

1. Art. 2을 Lei no 5.648/70.

2. Direito Processual Civil. 4. ed. São Paulo: Revista dos Tribunais. p. 104.

3. Teoria Geral do Processo. 12. ed. São Paulo: Malheiros, 1996. p. 260.

4. O italiano Francesco Carnelutti foi responsável pela disseminação do conceito de lide como um conflito de interesses qualificado por uma pretensão resistida. A função do processo, portanto, seria a de dar solução à lide. 